\title{
Pemetrexed Continuation Maintenance versus Conventional Platinum-Based Doublet Chemotherapy in EGFR-Negative Lung Adenocarcinoma: Retrospective Analysis
}

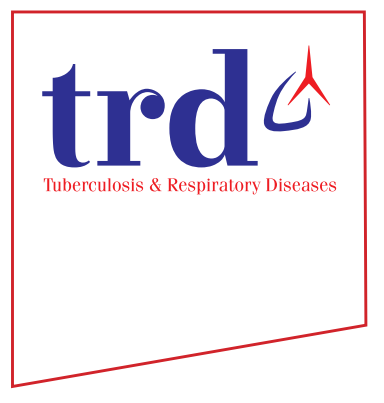

\author{
Seung Sook Paik, M.D. ${ }^{1}$, In Kyoung Hwang, M.D. ${ }^{1}$, Myung Jae Park, M.D., Ph.D. ${ }^{2}$ and Seung Hyeun \\ Lee, M.D., Ph.D. ${ }^{2}$ \\ ${ }^{1}$ Division of Pulmonary and Critical Care Medicine, Department of Internal Medicine, Dongnam Institute of Radiological \& \\ Medical Sciences, Busan, ${ }^{2}$ Division of Pulmonary and Critical Care Medicine, Department of Internal Medicine, Kyung Hee \\ University School of Medicine, Seoul, Korea
}

Background: Although targeted therapy and immuno-oncology have shifted the treatment paradigm for lung cancer, platinum-based combination is still the standard of care for advanced non-small cell lung cancer (NSCLC). Pemetrexed continuation maintenance therapy has been approved and increasingly used for patients with nonsquamous NSCLC. However, the efficacy of this strategy has not been proven in patients without driving mutations. The objective of this study was to compare the clinical benefit of pemetrexed continuation maintenance to conventional platinum-based doublet in epidermal growth factor receptor $(E G F R)$-negative lung adenocarcinoma.

Methods: A total of 114 patients with EGFR-negative lung adenocarcinoma who were treated with platinum doublet were retrospectively enrolled. We compared the survival rates between patients received pemetrexed maintenance after four-cycled pemetrexed/cisplatin and those received at least four-cycled platinum doublet without maintenance chemotherapy as a first-line treatment.

Results: Forty-one patients received pemetrexed maintenance and 73 received conventional platinum doublet. Median progression-free survival (PFS), which was defined as the time from the day of response evaluation after four cycles of chemotherapy to disease progression or death, was significantly higher in the pemetrexed maintenance group compared to conventional group (5.8 months vs. 2.2 months, $\mathrm{p}<0.001$ ). Median overall survival showed an increasing trend in the pemetrexed maintenance group (22.3 months vs. 16.1 months, $\mathrm{p}=0.098)$. Multivariate analyses showed that pemetrexed maintenance chemotherapy was associated with better PFS (hazard ratio, 0.73 ; 95\% confidence interval, $0.15-0.87$ ).

Conclusion: Compared to conventional platinum-based chemotherapy, premetrexed continuation maintenance treatment is associated with better clinical outcome for the patients with EGFR wild-type lung adenocarcinoma.

Keywords: Lung; Carcinoma; Pemetrexed; Chemotherapy; Platinum; Receptor, Epidermal Growth Factor

Address for correspondence: Seung Hyeun Lee, M.D., Ph.D.

Division of Pulmonary and Critical Care Medicine, Department of Internal Medicine, Kyung Hee University School of Medicine, 26 Kyungheedae-ro, Dongdaemun-gu, Seoul 02447, Korea

Phone: 82-2-958-8511, Fax: 82-2-968-1848, E-mail: humanmd04@hanmail.net

Received: Aug. 1, 2017, Revised: Sep. 23, 2017, Accepted: Oct. 2, 2017, Published online: Mar. 7, 2018

@(c) it is identical to the Creative Commons Attribution Non-Commercial License (http://creativecommons.org/licenses/by-nc/4.0/) 


\section{Introduction}

Despite numerous efforts for early detection and development of various treatment modalities, lung cancer is still the leading cause of cancer-related mortality worldwide ${ }^{1}$. Although, epidemiologic data showed an increasing trend for 5-year survival rate of lung cancer in Korea, 88,655 patients died from lung cancer during period of 2008 to $2012^{2}$. During last decades, great progress was made in the diagnosis and management of lung cancer, especially in the treatment of non-small cell lung cancer (NSCLC). Notably, moleculartargeted therapy including epidermal growth factor receptor tyrosine kinase inhibitors (EGFR-TKIs) and anaplastic lymphoma kinase (ALK) inhibitors has improved the survival of those harboring driving mutations ${ }^{3}$. Recently adopted immune checkpoint inhibitors targeting programmed death-l or programmed death ligand 1 (PD-L1) have improved survival in selected or unselected populations, and have expanded the lung cancer treatment options ${ }^{4-6}$. However, acquired resistance to EGFR-TKIs is unavoidable with median progression free survival of 10 months $^{7}$, and platinum-based chemotherapy is still a standard treatment in advanced NSCLC, especially for patients without driving mutations or low PD-L1 expression. $^{8}$.

Drugs which are recommended as partners in platinumbased chemotherapy regimens for first-line treatment of NSCLC include pemetrexed, gemcitabine, docetaxel, and paclitaxel $^{9}$. Pemetrexed is a multi-targeted antifolate drug that inhibits enzymes including thymidylate synthase, and dihydrofolate reductase that are involved in purine and pyrimidine synthesis $^{10}$. In a pivotal phase 3 trial, the pemetrexed/cisplatin combination showed better efficacy in lung adenocarcinoma compared to the gemcitabine/cisplatin combination ${ }^{11}$. In addition, the safety profile was better in patients treated with pemetrexed/cisplatin with less grade 3 or 4 toxicity compared with the gemcitabine/cisplatin group. Two subsequent studies conducted using the same design for Chinese and East Asian populations showed similar efficacy and safety profiles ${ }^{12,13}$. In addition, pemetrexed showed better efficacy when used in a maintenance regimen after four cycles of pemetrexed/ cisplatin combination compared to placebo without worsening quality of life ${ }^{14,15}$. Based on those studies, the pemetrexed/ cisplatin combination has become the preferred first-line treatment regimen in patients with nonsquamous NSCLC, and the current guideline recommends pemetrexed continuation maintenance therapy in those whose disease has not progressed after first-line pemetrexed/platinum chemotherapy ${ }^{8}$.

However, previous studies that proved the clinical benefit of this maintenance strategy enrolled patients regardless of the presence of driving mutations. Thus, no conclusions could be drawn about the difference response or efficacy according to patients' mutational status ${ }^{15,16}$. It is important to prove the effi- cacy of pemetrexed continuation maintenance chemotherapy for patients without driving mutations, as this maintenance strategy is currently utilized only in those patients in realworld practice. Moreover, the efficacy of pemetrexed-containing chemotherapy according to EGFR mutational status is still controversial $^{17,18}$.

Thus, we conducted this study to investigate whether pemetrexed continuation maintenance chemotherapy is more beneficial comparing conventional platinum-based chemotherapy without maintenance therapy in lung adenocarcinoma patients not harboring the EGFR mutation.

\section{Materials and Methods}

\section{Study subjects}

We retrospectively screened NSCLC patients who received platinum-based doublet first-line chemotherapy at Dongnam Institute of Radiological \& Medical Sciences, a secondary referral hospital located in Busan, South Korea, from January 2010 to July 2015 . Patients who were treated due to locally advanced or metastatic lung adenocarcinoma without $E G F R$ mutation were included. EGFR mutation was tested by pyrosequencing using EGFR Pyro Kit (QIAGEN Korea Ltd., Seoul, Korea). Patients who received concurrent chemoradiation or platinum doublet combined with bevacizumab, or who received a single chemotherapeutic agent, or received less than four cycles of first-line chemotherapy were excluded. We divided our population into pemetrexed continuation maintenance group and conventional treatment group; the former was defined as patients who did not show progression after four cycles of pemetrexed/cisplatin treatment and received pemetrexed continuation maintenance chemotherapy according to guideline ${ }^{8}$, and the latter was defined as those who received at least four-cycled platinum doublet without maintenance chemotherapy as a first-line treatment. Only the patients who showed non-progressive disease in the response evaluation after four cycles of chemotherapy were allocated to the conventional treatment group. Informed consents were obtained from all patients alive and the study protocol was approved by the Institutional Review Board of Dongnam Institute of Radiological \& Medical Sciences (D-1705-014-002).

\section{Data collection}

To obtain demographic information and clinical data, we reviewed the electronic medical records. Baseline characteristics including age, sex, Eastern Cooperative Oncology Group (ECOG) performance status, smoking status, stage, number of metastatic organs, presence of brain metastasis, tumor differentiation, and regimens used for each line of chemotherapy. 
Clinical stage was determined using chest computed tomography (CT), brain magnetic resonance imaging, and ${ }^{18} \mathrm{~F}$-fluorodeoxyglucose positron emission tomography based on the seventh lung cancer TNM classification and staging system ${ }^{19}$. Response to treatment was examined by CT every two cycles and evaluated according to the Response Evaluation Criteria in Solid Tumors (RECIST) $1.1^{20,21}$.

\section{Statistical analyses}

Statistical analyses were performed using the SPSS version 20.0 software for Windows (IBM Corp., Armonk, NY, USA). Progression-free survival (PFS) was defined as the time from

Table 1. Clinical characteristics of patients

\begin{tabular}{|c|c|c|c|c|}
\hline & \multirow{2}{*}{$\begin{array}{c}\text { No. of } \\
\text { patients } \\
(\%)\end{array}$} & \multicolumn{2}{|c|}{ Treatment groups } & \multirow[b]{2}{*}{$\begin{array}{c}\text { p- } \\
\text { value }\end{array}$} \\
\hline & & $\begin{array}{l}\text { Pemetrexed } \\
\text { maintenance }\end{array}$ & $\begin{array}{l}\text { Conventional } \\
\text { chemotherapy }\end{array}$ & \\
\hline All & $114(100)$ & $41(36)$ & $73(64)$ & \\
\hline Sex & & & & 0.273 \\
\hline Female & $35(31)$ & $10(25)$ & $25(34)$ & \\
\hline Male & 79 (69) & $31(75)$ & $48(66)$ & \\
\hline Age, yr & & & & 0.208 \\
\hline$<65$ & $59(52)$ & $18(44)$ & $41(56)$ & \\
\hline$\geq 65$ & $55(48)$ & $23(56)$ & $32(44)$ & \\
\hline Smoking & & & & 0.890 \\
\hline Never & 38 (33) & $14(34)$ & $24(33)$ & \\
\hline Ever & $76(67)$ & 27 (66) & $49(67)$ & \\
\hline $\begin{array}{l}\text { ECOG perfor- } \\
\text { mance status }\end{array}$ & & & & 0.541 \\
\hline 0,1 & $95(83)$ & $33(80)$ & $62(84)$ & \\
\hline$\geq 2$ & $19(17)$ & $8(20)$ & $11(16)$ & \\
\hline T stage & & & & 0.614 \\
\hline $\mathrm{T} 1$ & $7(6)$ & $3(7)$ & $4(5)$ & \\
\hline$\geq \mathrm{T} 2$ & 107 (94) & 38 (93) & 69 (95) & \\
\hline $\mathrm{N}$ stage & & & & 0.855 \\
\hline No & $9(8)$ & $4(10)$ & $5(7)$ & \\
\hline$\geq \mathrm{N} 1$ & $105(92)$ & 37 (90) & 68 (93) & \\
\hline Stage & & & & 0.215 \\
\hline IIIB & $10(9)$ & $2(5)$ & $8(11)$ & \\
\hline IV & $104(91)$ & 39 (95) & $65(89)$ & \\
\hline $\begin{array}{l}\text { Metastatic } \\
\text { organs }\end{array}$ & & & & 0.329 \\
\hline $0-2$ & $72(63)$ & $30(73)$ & $42(56)$ & \\
\hline$\geq 3$ & $42(37)$ & $11(27)$ & $31(44)$ & \\
\hline
\end{tabular}

(Continued) the day of response evaluation after four cycles of chemotherapy to disease progression or death from any cause. Overall survival (OS) was defined as the time from the first day of chemotherapy to death from any cause. Associations between categorical variables were compared using the chi-square test. Associations between clinicopathological parameters and survival were evaluated by univariate analysis using the logrank test. Subsequently, multivariate Cox's proportional hazard regression was conducted with adjustment for parameters

Table 1. Continued

\begin{tabular}{|c|c|c|c|c|}
\hline & & Treatme & ent groups & \\
\hline & $\begin{array}{l}\text { patients } \\
(\%)\end{array}$ & $\begin{array}{l}\text { Pemetrexed } \\
\text { maintenance }\end{array}$ & $\begin{array}{l}\text { Conventional } \\
\text { chemotherapy }\end{array}$ & $\begin{array}{c}\text { p- } \\
\text { value }\end{array}$ \\
\hline $\begin{array}{l}\text { Brain } \\
\text { metastasis }\end{array}$ & & & & 0.182 \\
\hline No & $70(61)$ & $29(70)$ & $41(55)$ & \\
\hline Yes & $44(39)$ & $12(30)$ & $32(43)$ & \\
\hline $\begin{array}{l}A L K \text { transloca- } \\
\text { tion* }\end{array}$ & & & & 0.711 \\
\hline Negative & $45(83)$ & $16(80)$ & $29(85)$ & \\
\hline Positive & $9(16)$ & $4(20)$ & $5(15)$ & \\
\hline KRAS mutation* & & & & 0.168 \\
\hline Negative & $36(83)$ & $11(100)$ & $25(66)$ & \\
\hline Positive & $7(17)$ & $0(0)$ & $7(34)$ & \\
\hline Differentiation & & & & 0.276 \\
\hline Well & 78 (69) & $30(74)$ & $48(66)$ & \\
\hline Moderate-poor & $36(31)$ & $11(26)$ & $25(34)$ & \\
\hline $\begin{array}{l}\text { Second-line } \\
\text { treatment }\end{array}$ & & & & 0.805 \\
\hline Yes & $82(72)$ & $29(70)$ & $53(73)$ & \\
\hline No & $18(28)$ & $12(30)$ & $6(27)$ & \\
\hline $\begin{array}{l}\text { Second-line } \\
\text { regimens }^{\dagger}\end{array}$ & & & & 0.279 \\
\hline EGFR-TKIs & $26(32)$ & $8(27)$ & $18(34)$ & \\
\hline Pemetrexed & $14(17)$ & - & $14(26)$ & \\
\hline Gemcitabine & $15(18)$ & $9(31)$ & $6(11)$ & \\
\hline Vinorelbine & $10(12)$ & $6(21)$ & $4(8)$ & \\
\hline Taxens & $11(13)$ & $4(14)$ & $7(12)$ & \\
\hline Crizotinib & $6(7)$ & $2(7)$ & $4(8)$ & \\
\hline
\end{tabular}

Values are presented as number (\%).

* $A L K$ translocation and KRAS mutation data were available in 54 and 43 patients, respectively. ${ }^{\dagger} 82$ patients received second-line treatment

ECOG: Eastern Cooperative Oncology Group; T: tumor; N: lymph node; $A L K$ : anaplastic lymphoma kinase; KRAS: Kirsten rat sarcoma; EGFR-TKI: epidermal growth factor receptor tyrosine kinase inhibitor. 
with p-values $<0.3$ in the univariate analysis. Survival probability was estimated by the Kaplan-Meier method. A p-value $<0.05$ was considered statistically significant.

\section{Results}

\section{Patient characteristics}

During the study period, 584 patients received chemotherapy for NSCLC at our institution. Of these, 171 received platinum-based doublet first-line chemotherapy due to locally advanced or metastatic EGFR-negative lung adenocarcinoma. After excluding patients who met the predefined exclusion criteria, 114 were eligible for this study.

The clinicopathological characteristics of the patients are summarized in Table 1. All subjects were Korean. Their median age was 66 years (range, $32-79$ years). 79 patients (69\%) were male and 55 patients (48\%) were over 65 years of age. 76 patients $(67 \%)$ were current or former smokers. 95 patients (83\%) had ECOG performance status of 0 or 1.104 patients (91\%) were in stage IV and 78 patients (69\%) had well-differentiated cancer. Forty-two patients (37\%) had metastases at more than three organs and 44 patients (39\%) had brain metastasis. Tests for $A L K$ translocation including immunohistochemistry and fluorescence in situ hybridization was performed in 54 patients (47\%) among whom nine patients (16\%) were positive for $A L K$ translocation.

Out of 114 patients, 41 were treated with pemetrexed maintenance chemotherapy and 73 received conventional platinum-based chemotherapy as a first-line treatment. In the maintenance group, the median numbers of cycles of maintenance chemotherapy were 4 (range, 1-25). The regimens used for first-line chemotherapy in the conventional treatment group were pemetrexed/platinum $(\mathrm{n}=41,56 \%)$, gemcitabine/ platinum $(n=16,22 \%)$, paclitaxel/platinum $(n=9,12 \%)$, and docetaxel/platinum ( $n=7,10 \%)$. The numbers of patients who received four-, five-, and six-cycled first-line chemotherapy in the conventional treatment group were, 27,16 , and 30 , respectively. Of all patients, 82 patients $(72 \%)$ received second-line or further treatment. Second-line treatment regimens were pemetrexed $(n=14,17 \%)$, gemcitabine $(n=15,18 \%)$, taxens $(\mathrm{n}=11,13 \%)$, vinorelbine $(\mathrm{n}=10,12 \%)$, erlotinib $(\mathrm{n}=12,15 \%)$, and gefitinib $(n=14,17 \%)$. Forty-one patients $(50 \%)$ received the third-line treatment with gemcitabine $(n=6,15 \%)$, vinorelbine $(\mathrm{n}=13,32 \%)$, pemetrexed $(\mathrm{n}=9,22 \%)$, taxens $(\mathrm{n}=7,17 \%)$, or gefitinib $(\mathrm{n}=6,16 \%)$. There were no significant differences between the two treatment groups in terms of clinicopathological characteristics or proportion of patients who received second-line or further treatment (Table 1).

\section{PFS according to different treatment}

Survival analyses results according to the clinicopathological parameters are summarized in Table 2. The median PFS for the overall population was 3.3 months (95\% confidence interval [CI], 2.4-3.7 months). Univariate analysis showed that metastases in less than three organs (4.3 months vs. 2.9 months, $\mathrm{p}=0.039$ ) and absence of KRAS mutation (4.1 months vs. 2.4 months, $\mathrm{p}=0.042$ ) were significantly associated with better PFS. In addition, median PFS of the maintenance chemotherapy group was significantly higher compared with conventional chemotherapy group (5.8 months vs. 2.2 months, $\mathrm{p}<0.001)$. In the multivariate analysis, less advanced stage (hazard ratio [HR], 0.81; 95\% CI, 0.64-0.97) and treatment with pemetrexed maintenance (HR, 0.73 ; 95\% CI, 0.15-0.87) were significantly associated with better PFS. Kaplan-Meier survival curves also showed that patients treated with pemetrexed maintenance chemotherapy were likely to have better survival in terms of PFS (Figure 1A).

\section{OS according to different treatment}

The median OS for all study subjects was 17.1 months (95\% CI, 14.8-19.2 months). Univariate analysis revealed that female gender, young age, and no smoking history showed a trend to association with better OS, and good performance status (21.6 months vs. 16.9 months, $\mathrm{p}=0.003$ ), less advanced stage (19.1 months vs. 13.2 months, $\mathrm{p}=0.041$ ), and receiving second-line treatment ( 20.5 months vs. 15.1 months, $\mathrm{p}=0.049$ ) were significantly associated with better OS. Treatment with pemetrexed maintenance chemotherapy showed trend of association with longer OS (22.3 months vs. 16.1 months, $\mathrm{p}=0.098$ ). Multivariate analysis showed that female gender (HR, 0.68; 95\% CI, 0.23-0.87), good performance status (HR, $0.77 ; 95 \%$ CI, 0.24-0.91) and less advanced stage (HR, 0.83; $95 \%$ CI, 0.35-0.89) were significantly associated with better OS. Kaplan-Meier survival curves also showed that patients treated with pemetrexed maintenance chemotherapy were likely to have longer OS, although it was not statistically significant (Figure 1B).

\section{Discussion}

The current data demonstrate that pemetrexed continuation maintenance chemotherapy is significantly associated with better clinical outcome in EGFR-negative lung adenocarcinoma compared with conventional platinum-based doublet chemotherapy as a first-line treatment. The PFS benefit was significant even after adjusting for several clinical variables. In addition, pemetrexed maintenance treatment showed a trend associated with better OS, although not statistically significant. To the best of our knowledge, this is the first study demonstrat- 
Table 2. Survival analyses results according to clinicopathologic parameters in all study subjects

\begin{tabular}{|c|c|c|c|c|c|c|c|}
\hline & \multirow[b]{2}{*}{$\begin{array}{c}\text { No. of } \\
\text { patients } \\
(\%)\end{array}$} & \multicolumn{3}{|c|}{ Progression-free survival (PFS) } & \multicolumn{3}{|c|}{ Overall survival (OS) } \\
\hline & & $\begin{array}{c}\text { Median PFS } \\
(\mathrm{mo})\end{array}$ & $\begin{array}{c}\text { Univariate } \\
\text { analysis } \\
\text { p-value }\end{array}$ & $\begin{array}{c}\text { Multivariate } \\
\text { analysis } \\
\text { adjusted HR } \\
(95 \% \mathrm{CI})\end{array}$ & $\begin{array}{l}\text { Median OS } \\
\text { (mo) }\end{array}$ & $\begin{array}{c}\text { Univariate } \\
\text { analysis } \\
\text { p-value }\end{array}$ & $\begin{array}{c}\text { Multivariate } \\
\text { analysis } \\
\text { adjusted HR } \\
(95 \% \mathrm{CI})\end{array}$ \\
\hline All & $114(100)$ & 3.3 & & & 17.1 & & \\
\hline Sex & & & 0.921 & NA & & 0.078 & \\
\hline Female & $35(31)$ & 3.5 & & & 19.2 & & $0.68(0.23-0.87)$ \\
\hline Male & $79(69)$ & 2.8 & & & 15.4 & & Reference \\
\hline Age, yr & & & 0.543 & NA & & 0.117 & \\
\hline$<65$ & $59(52)$ & 3.7 & & & 19.7 & & $0.98(0.73-1.93)$ \\
\hline$\geq 65$ & $55(48)$ & 2.8 & & & 14.4 & & Reference \\
\hline Smoking & & & 0.427 & NA & & 0.197 & \\
\hline Never & $38(33)$ & 3.6 & & & 18.2 & & $0.94(0.54-2.10)$ \\
\hline Ever & $76(67)$ & 2.9 & & & 15.0 & & Reference \\
\hline ECOG performance status & & & 0.344 & NA & & 0.003 & \\
\hline 0,1 & $95(83)$ & 3.3 & & & 21.6 & & $0.77(0.24-0.91)$ \\
\hline$\geq 2$ & $19(17)$ & 2.5 & & & 16.9 & & Reference \\
\hline T stage & & & 0.610 & $\mathrm{NA}$ & & 0.712 & NA \\
\hline $\mathrm{T} 1$ & $7(6)$ & 3.3 & & & 17.8 & & \\
\hline$\geq \mathrm{T} 2$ & $107(94)$ & 2.6 & & & 15.4 & & \\
\hline N stage & & & 0.392 & NA & & 0.614 & NA \\
\hline N0 & $9(8)$ & 3.4 & & & 17.5 & & \\
\hline$\geq \mathrm{N} 1$ & $105(92)$ & 2.8 & & & 16.0 & & \\
\hline Stage & & & 0.267 & & & 0.041 & \\
\hline IIIB & $10(9)$ & 4.6 & & $0.81(0.64-0.97)$ & 19.1 & & $0.83(0.35-0.89)$ \\
\hline IV & $104(91)$ & 2.9 & & Reference & 13.2 & & Reference \\
\hline Metastatic organs & & & 0.039 & & & 0.344 & NA \\
\hline $0-2$ & $72(63)$ & 4.3 & & $0.84(0.54-1.40)$ & 18.7 & & \\
\hline$\geq 3$ & $42(37)$ & 2.9 & & Reference & 17.1 & & \\
\hline Brain metastasis & & & 0.687 & NA & & 0.373 & NA \\
\hline No & $70(61)$ & 3.3 & & & 17.1 & & \\
\hline Yes & $44(39)$ & 3.2 & & & 16.4 & & \\
\hline$A L K$ translocation* & & & 0.307 & NA & & 0.483 & NA \\
\hline Negative & $45(83)$ & 3.3 & & & 17.5 & & \\
\hline Positive & $9(16)$ & 2.9 & & & 16.9 & & \\
\hline KRAS mutation* & & & 0.042 & & & 0.590 & NA \\
\hline Negative & $36(83)$ & 4.1 & & $0.91(0.34-1.99)$ & 18.1 & & \\
\hline Positive & $7(17)$ & 2.4 & & Reference & 14.8 & & \\
\hline Differentiation & & & 0.318 & NA & & 0.721 & NA \\
\hline Well & $78(69)$ & 3.6 & & & 18.1 & & \\
\hline Moderate-poor & $36(31)$ & 3.2 & & & 16.2 & & \\
\hline Second-line treatment ${ }^{\dagger}$ & & & 0.519 & NA & & 0.049 & \\
\hline Yes & $82(72)$ & 3.4 & & & 20.5 & & $0.95(0.31-1.92)$ \\
\hline No & $18(28)$ & 3.1 & & & 15.1 & & Reference \\
\hline First-line treatment & & & $<0.001$ & & & 0.098 & \\
\hline Conventional & $73(64)$ & 2.2 & & Reference & 16.1 & & Reference \\
\hline Pemetrexed maintenance & $41(36)$ & 5.8 & & $0.73(0.15-0.87)$ & 22.3 & & $0.87(0.28-2.16)$ \\
\hline
\end{tabular}

HR: hazard ratio; CI: confidence interval; NA: not applicable; ECOG: Eastern Cooperative Oncology Group; T: tumor; N: lymph node; $A L K$ : anaplastic lymphoma kinase; $K R A S$ : Kirsten rat sarcoma.

${ }^{*} A L K$ translocation and $K R A S$ mutation data were available in 54 and 43 patients, respectively. ${ }^{\dagger} 82$ patients received second line treatment. 

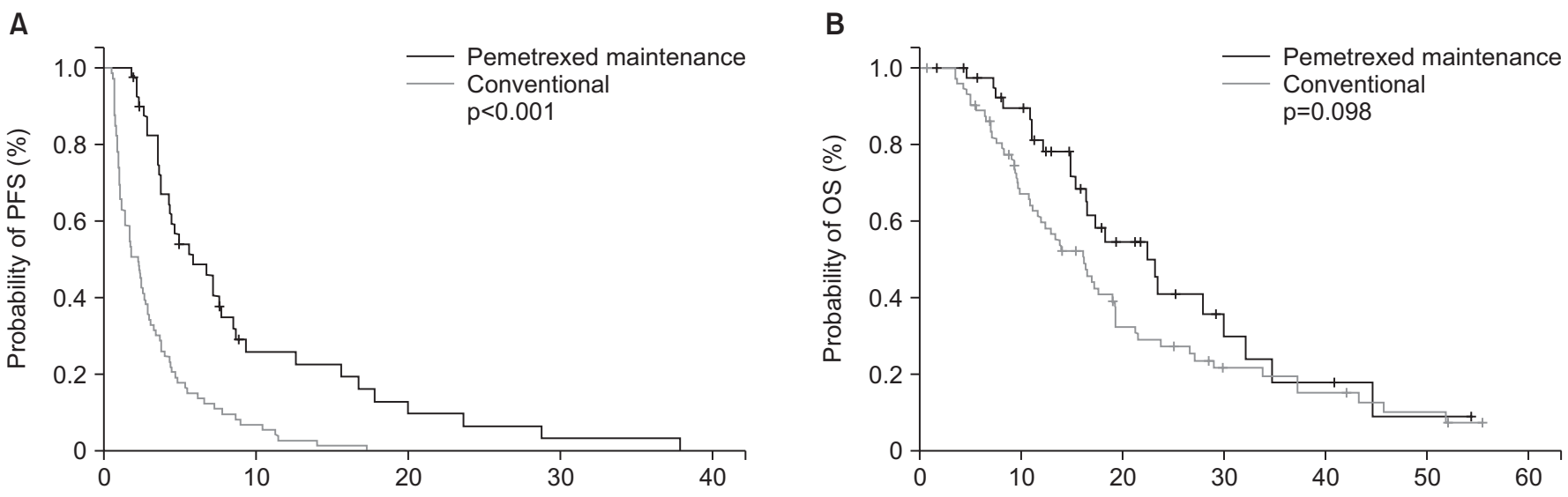

Figure 1. Kaplan-Meier survival curves for progression-free survival (PFS) (A) and overall survival (OS) (B) in all patients. The p-values were determined using the log-rank test.

ing the superiority of pemetrexed continuation maintenance strategy over conventional four- or six-cycled platinum-based approach in patients with $E G F R$ wild-type lung adenocarcinoma.

Maintenance chemotherapy has emerged as a promising strategy for the management of advanced NSCLC patients ${ }^{21}$. The main purpose of this approach is to improve survival by prolonging tumor response by administrating well-tolerated drug in patients who have not progressed during first-line or induction treatments. Several regimens are recommended for continuation or switch maintenance chemotherapy in NSCLC $^{22,23}$. However, pemetrexed continuation maintenance is only regimen covered by the National Health Insurance Service of Korea as a continuation maintenance chemotherapy. The clinical benefit of pemetrexed continuation maintenance chemotherapy was first demonstrated in a small phase 2 trial comparing pemetrexed versus placebo after firstline chemotherapy ${ }^{24}$. A subsequent landmark phase 3 trial (PARAMOUNT) showed clinical efficacy of this maintenance strategy after four cycles of pemetrexed/cisplatin regarding both PFS (4.1 months vs. 2.8 months; HR, 0.62; $\mathrm{p}<0.0001$ ) and OS (13.9 months vs. 11.0 months; HR, $0.78 ; \mathrm{p}=0.0195)^{15,25}$. The quality of life during maintenance therapy was not different in both treatment groups, except for an increased loss of appetite and a delayed worsening of pain and hemoptysis in the maintenance treatment group ${ }^{14}$. As pemetrexed-containing chemotherapy is no longer recommended as a first-line treatment for NSCLC patients harboring EGFR mutation, a re-evaluation is necessary to determine whether pemetrexed maintenance chemotherapy is clinically beneficial when applied to patients without $E G F R$ mutations.

Although there has been no direct evidence that pemetrexed continuation maintenance is effective even in EGFR wild-type NSCLC patients, we could expect positive results based on the previous studies. In the phase 2 trial by Mubarak et al. $^{24}$, which first demonstrated a clinical efficacy of this treatment strategy, $94 \%$ were Caucasian, $68 \%$ were male, and $60 \%$ were smokers. Similarly, in the phase 3 PARAMOUNT trial, $96 \%$ of study subjects were Caucasian, $58 \%$ were male, and $79 \%$ were smokers ${ }^{15}$. As Caucasians, males, and smokers are generally more likely not to have EGFR mutation, we can speculate that most of population in those trials was $E G F R$ wild-type.

The prognostic impact of EGFR mutation status in the pemetrexed-containing treatment in NSCLC seems to be debatable. Jiang et al. ${ }^{26}$ reported significant better overall response rate and median PFS in the EGFR-mutated lung adenocarcinoma patients receiving first-line pemetrexed/ platinum combinations compared to those without $E G F R$ mutation. In contrast, Park et al. ${ }^{17}$ recently demonstrated the significant association of the EGFR mutation with poor PFS in nonsquamous NSCLC patients treated with first-line pemetrexed-containing chemotherapy. In our study, the median OS for pemetrexed maintenance was 22.3 months which is much longer than those of previous trials. The median OS in the PARAMOUNT trial and the aforementioned phase 2 trial were 13.9 and 15.4 months, respectively ${ }^{15,24}$. Although, we cannot exactly explain the reason for the survival differences between our data and those from previous studies, the better survival in our study could be attributed to the relatively high proportion of patients who received subsequent treatment in the maintenance group (70\%), less use of EGER-TKIs in second-line treatment (20\%), and the exclusion of EGFR-positive patients.

Of note, receiving second-line treatment or not, and which regimen is used for second-line treatment can influence the survival in advanced NSCLC patients. Pemetrexed has been one of the recommended drugs for those progressed after first-line platinum-doublet chemotherapy, based on the data from a phase III study demonstrating clinical benefit of pemetrexed in terms of PFS (2.9 months) and 1-year survival rate $(29.7 \%)$ as a second-line treatment for advanced NSCLC ${ }^{27}$. Yoh et al. ${ }^{28}$ recently reported that the median OS was signifi- 
cantly lower in NSCLC patient treated only with maintenance chemotherapy compared with those received timely secondline treatment after maintenance chemotherapy. In addition, they demonstrated that median OS of patients treated with conventional first-line chemotherapy without maintenance and with timely second-line treatment was similar to the OS of those who received maintenance therapy without subsequent treatment (17.7 months and 13.1 months, respectively ${ }^{28}$. In addition, a recent meta-analysis showed that treatment with EGFR-TKIs was associated with inferior efficacy when used in the second-line therapy for those without $E G F R$ mutations ${ }^{29}$. In our study, $70 \%$ of patients in maintenance group received second-line or further treatment, which is relatively higher compared with that of PARAMOUNT study $(58 \%)^{25}$. Moreover, EGFR-TKIs were less frequently used for second-line treatment after maintenance therapy in our study compared to the previous trial $(20 \% \text { vs. } 31 \%)^{25}$. Although the clinical impact of EGFR-TKIs after progression in the pemetrexed continuation maintenance treatment has not been evaluated, out data indirectly suggest the EGFR-TKI may be disadvantageous as a subsequent treatment in this maintenance setting. Whether EGFR mutation is a negative predictive factor in the pemetrexed maintenance chemotherapy and which treatment regimen is the most beneficial after progression of this maintenance strategy need to be investigated.

We must note some limitations in this study. First, this study was performed retrospectively in a single institution and included a relatively small sample size. Second, the biomarkers that might be associated with response to pemetrexed including thymidylate synthase were not evaluated simultaneously. Third, the $A L K$ translocation test was performed only in a portion of the population, thus the possible influence of this driving rearrangement on the clinical outcome could not be excluded. Although conflicting data exist, several studies have suggested that $A L K$ rearrangement may be associated with better clinical outcome for those treated with pemetrexedbased chemotherapy than wild-type for $A L K^{17,30}$. Fourth, treatment-related quality of life and side effects according to different treatment strategy were not investigated. However, the strength of this study is in that we demonstrate the clinical efficacy of pemetrexed maintenance chemotherapy reflecting current real-world clinical practice.

In conclusion, the present data showed the survival benefit of pemetrexed continuation maintenance chemotherapy over conventional four- or six-cycle chemotherapy in patients with $E G F R$ wild-type lung adenocarcinoma. Our study confirmed the previous results deduced from several pivotal studies which included non-selective patients, and indicates the clinical utility of maintenance treatment using pemetrexed in realworld practice. Large scale, prospective studies including $E G F R / A L K$ dual-negative population and analyzing predictive value of candidate biomarkers will provide more practical information about this treatment strategy for the lung cancer management.

\section{Conflicts of Interest}

No potential conflicts of interest relevant to this article have been reported.

\section{Acknowledgments}

This work was supported by the National Research Foundation of Korea (NRF) grant funded by the funded by the Ministry of Science, ICT \& Future Planning (grant No. NRF2017R1C1B5016828) given to SH Lee.

\section{References}

1. Torre LA, Bray F, Siegel RL, Ferlay J, Lortet-Tieulent J, Jemal A. Global cancer statistics, 2012. CA Cancer J Clin 2015;65:87108.

2. Park JY, Jang SH. Epidemiology of Lung Cancer in Korea: Recent Trends. Tuberc Respir Dis (Seoul) 2016;79:58-69.

3. Bansal P, Osman D, Gan GN, Simon GR, Boumber Y. Recent advances in targetable therapeutics in metastatic non-squamous NSCLC. Front Oncol 2016;6:112

4. Reck M, Rodriguez-Abreu D, Robinson AG, Hui R, Csoszi T, Fulop A, et al. Pembrolizumab versus chemotherapy for PD-L1-positive non-small-cell lung cancer. N Engl J Med 2016;375:1823-33.

5. Peters S, Gettinger S, Johnson ML, Janne PA, Garassino MC, Christoph D, et al. Phase II trial of atezolizumab as first-line or subsequent therapy for patients with programmed deathligand 1-selected advanced non-small-cell lung cancer (BIRCH). J Clin Oncol 2017;35:2781-9.

6. Borghaei H, Paz-Ares L, Horn L, Spigel DR, Steins M, Ready NE, et al. Nivolumab versus docetaxel in advanced nonsquamous non-small-cell lung cancer. N Engl J Med 2015;373:1627-39.

7. Chang YS, Choi CM, Lee JC. Mechanisms of Epidermal Growth Factor Receptor Tyrosine Kinase Inhibitor Resistance and Strategies to Overcome Resistance in Lung Adenocarcinoma. Tuberc Respir Dis (Seoul) 2016;79:248-56.

8. National Comprehensive Cancer Network guidelines [Internet]. Fort Washington: National Comprehensive Cancer Network; 2017 [cited 2017 Jul 15]. Available from: http://www. nccn.org/professionals/physician_gls/pdf/nscl.pdf.

9. Masters GA, Temin S, Azzoli CG, Giaccone G, Baker S Jr Brahmer JR, et al. Systemic therapy for stage IV non-small-cell lung cancer: American Society of Clinical Oncology clinical practice guideline update. J Clin Oncol 2015;33:3488-515.

10. Joerger M, Omlin A, Cerny T, Fruh M. The role of pemetrexed 
in advanced non small-cell lung cancer: special focus on pharmacology and mechanism of action. Curr Drug Targets 2010;11:37-47.

11. Scagliotti GV, Parikh P, von Pawel J, Biesma B, Vansteenkiste J, Manegold C, et al. Phase III study comparing cisplatin plus gemcitabine with cisplatin plus pemetrexed in chemotherapy-naive patients with advanced-stage non-small-cell lung cancer. J Clin Oncol 2008;26:3543-51.

12. Wu YL, Lu S, Cheng Y, Zhou C, Wang M, Qin S, et al. Efficacy and safety of pemetrexed/cisplatin versus gemcitabine/cisplatin as first-line treatment in Chinese patients with advanced nonsquamous non-small cell lung cancer. Lung Cancer 2014;85:401-7.

13. Yang CH, Simms L, Park K, Lee JS, Scagliotti G, Orlando M. Efficacy and safety of cisplatin/pemetrexed versus cisplatin/ gemcitabine as first-line treatment in East Asian patients with advanced non-small cell lung cancer: results of an exploratory subgroup analysis of a phase III trial. J Thorac Oncol 2010;5:688-95.

14. Belani CP, Brodowicz T, Ciuleanu TE, Krzakowski M, Yang SH, Franke F, et al. Quality of life in patients with advanced non-small-cell lung cancer given maintenance treatment with pemetrexed versus placebo (H3E-MC-JMEN): results from a randomised, double-blind, phase 3 study. Lancet Oncol 2012;13:292-9.

15. Paz-Ares LG, de Marinis F, Dediu M, Thomas M, Pujol JL, Bidoli P, et al. PARAMOUNT: Final overall survival results of the phase III study of maintenance pemetrexed versus placebo immediately after induction treatment with pemetrexed plus cisplatin for advanced nonsquamous non-small-cell lung cancer. J Clin Oncol 2013;31:2895-902.

16. Belani CP, Wu YL, Chen YM, Kim JH, Yang SH, Zhang L, et al. Efficacy and safety of pemetrexed maintenance therapy versus best supportive care in patients from East Asia with advanced, nonsquamous non-small cell lung cancer: an exploratory subgroup analysis of a global, randomized, phase 3 clinical trial. J Thorac Oncol 2012;7:567-73.

17. Park S, Kim HJ, Choi CM, Lee DH, Kim SW, Lee JS, et al. Predictive factors for a long-term response duration in nonsquamous cell lung cancer patients treated with pemetrexed. BMC Cancer 2016;16:417.

18. Park S, Park TS, Choi CM, Lee DH, Kim SW, Lee JS, et al. Survival benefit of pemetrexed in lung adenocarcinoma patients with anaplastic lymphoma kinase gene rearrangements. Clin Lung Cancer 2015;16:e83-9.

19. Goldstraw P. The 7th edition of TNM in lung cancer: what now? J Thorac Oncol 2009;4:671-3.

20. Eisenhauer EA, Therasse P, Bogaerts J, Schwartz LH, Sargent $\mathrm{D}$, Ford R, et al. New response evaluation criteria in solid tumours: revised RECIST guideline (version 1.1). Eur J Cancer 2009;45:228-47.
21. Hwang KE, Kim HR. Response Evaluation of Chemotherapy for Lung Cancer. Tuberc Respir Dis (Seoul) 2017;80:136-42.

22. Gerber DE, Rasco DW, Le P, Yan J, Dowell JE, Xie Y. Predictors and impact of second-line chemotherapy for advanced nonsmall cell lung cancer in the United States: real-world considerations for maintenance therapy. J Thorac Oncol 2011;6:36571.

23. Ciuleanu T, Brodowicz T, Zielinski C, Kim JH, Krzakowski M, Laack E, et al. Maintenance pemetrexed plus best supportive care versus placebo plus best supportive care for non-smallcell lung cancer: a randomised, double-blind, phase 3 study. Lancet 2009;374:1432-40.

24. Cappuzzo F, Ciuleanu T, Stelmakh L, Cicenas S, Szczesna A, Juhasz E, et al. Erlotinib as maintenance treatment in advanced non-small-cell lung cancer: a multicentre, randomised, placebo-controlled phase 3 study. Lancet Oncol 2010;11:5219 .

25. Mubarak N, Gaafar R, Shehata S, Hashem T, Abigeres D, Azim $\mathrm{HA}$, et al. A randomized, phase 2 study comparing pemetrexed plus best supportive care versus best supportive care as maintenance therapy after first-line treatment with pemetrexed and cisplatin for advanced, non-squamous, non-small cell lung cancer. BMC Cancer 2012;12:423.

26. Paz-Ares L, de Marinis F, Dediu M, Thomas M, Pujol JL, Bidoli $\mathrm{P}$, et al. Maintenance therapy with pemetrexed plus best supportive care versus placebo plus best supportive care after induction therapy with pemetrexed plus cisplatin for advanced non-squamous non-small-cell lung cancer (PARAMOUNT): a double-blind, phase 3, randomised controlled trial. Lancet Oncol 2012;13:247-55.

27. Jiang X, Yang B, Lu J, Zhan Z, Li K, Ren X. Pemetrexed-based chemotherapy in advanced lung adenocarcinoma patients with different EGFR genotypes. Tumour Biol 2015;36:861-9.

28. Hanna N, Shepherd FA, Fossella FV, Pereira JR, De Marinis F, von Pawel J, et al. Randomized phase III trial of pemetrexed versus docetaxel in patients with non-small-cell lung cancer previously treated with chemotherapy. J Clin Oncol 2004;22:1589-97.

29. Yoh K, Goto Y, Naito Y, Kishi K, Mori K, Hotta K, et al. Impact of maintenance therapy for patients with non-small cell lung cancer in a real-world setting. Anticancer Res 2017;37:150713.

30. Lee JK, Hahn S, Kim DW, Suh KJ, Keam B, Kim TM, et al. Epidermal growth factor receptor tyrosine kinase inhibitors vs conventional chemotherapy in non-small cell lung cancer harboring wild-type epidermal growth factor receptor: a meta-analysis. JAMA 2014;311:1430-7.

31. Lee JO, Kim TM, Lee SH, Kim DW, Kim S, Jeon YK, et al. Anaplastic lymphoma kinase translocation: a predictive biomarker of pemetrexed in patients with non-small cell lung cancer. J Thorac Oncol 2011;6:1474-80. 